\title{
Automated System for Capture and Detection of Nucleic Acids
}

\author{
A. Brown, A.A. Akinsanya, S.J. Barker, M. Brophy, A.K. Dobb, S.M. Doyle, \\ I.R. Hudson, S.J. Minter, M.J. Wraith and J.D. Oultram \\ Tepnel Life Sciences PLC, Manchester, England, UK
}

BioTechniques 27:176-180 (July 1999)

\begin{abstract}
A fully automated nucleic acid analysis system is described, which offers positive sample identification, improved sensitivity and reduced user interaction compared to conventional techniques. The system relies on the sequence-specific capture of DNA onto solidphase particles, confirming product identity without the problems of interpretation and lack of sequence information inherent in gelbased analyses. The system can be used for sequence confirmation, mutation analysis and semiquantitative detection of $P C R$ products.
\end{abstract}

\section{INTRODUCTION}

The ability to specifically amplify very small amounts of DNA has made the polymerase chain reaction (PCR) (5) an invaluable tool in areas such as diagnostic research, bio-pharmaceutical development, genetic analysis, forensics and environmental testing. High-performance thermal cycler systems (4) have increased the speed of PCRs, while recent developments such as the ABI PRISM ${ }^{\circledR} 7700$ Sequence Detection System (PE Biosystems, Warrington, Cheshire, England, UK) and the LightCycler ${ }^{\mathrm{TM}}$ System (Roche Diagnostics Ltd., Lewes, East Sussex, England, UK) have eliminated the need for a subsequent detection step by performing PCR with online analysis. However, for most investigations, the overall analysis time is still largely determined by the existing methods for detection of the PCR products. The most commonly applied detection method, agarose gel electrophoresis (AGE) with ethidium bromide staining, does not lend itself to automation, is time-consuming and requires substantial user input. More importantly, the sensitivity of detection is limited to approximately 5-10 ng of DNA fragment, the analysis can be subjective, and the results provide no sequence confirmation of the PCR product.

The DARAS ${ }^{\circledR}$ system (Tepnel Life Sciences PLC, Manchester, England, UK) described here applies solid-phase chemistry and precise temperature control of critical steps to the automated analysis of up to 100 PCR products per day, providing results for up to 12 samples in $45 \mathrm{~min}$. Target-specific micro-beads contained in disposable reaction columns ensure accurate and sensitive identification without the associated problems of conventional methods. PC-based, userfriendly software enables protocol optimization, data collection, full sample analysis and traceability.

\section{MATERIALS AND METHODS}

All oligonucleotides were synthesized on a Model 394 DNA/RNA Synthesizer (PE Biosystems) using standard phosphoramidite chemistries (2) and purified by reverse-phase HPLC (ÄKTA ${ }^{\text {TM }}$ purifier 10 XT system; Amersham Pharmacia Biotech UK Ltd., Little Chalfont, Bucks, England, UK). Capture probes were synthesized with a $5^{\prime}$ amino modification, detection probes and labeled PCR primers with a $5^{\prime}$ biotin label.

PCRs were performed using the MJ Research PTC-200 DNA Engine ${ }^{\mathrm{TM}}$ [Genetic Research Instrumentation (GRI) Ltd., Braintree, Essex, England, UK] with 0.2-mL, thinwalled reaction tubes (GRI Ltd.) for 30 cycles $\left(95^{\circ} \mathrm{C}\right.$ for 3 $\min , 30 \times\left[95^{\circ} \mathrm{C}\right.$ for $1 \mathrm{~min}, 60^{\circ} \mathrm{C}$ for $1 \mathrm{~min}$ and $72^{\circ} \mathrm{C}$ for 2 $\min$ ], $72^{\circ} \mathrm{C}$ for $2 \mathrm{~min}$ and $4^{\circ} \mathrm{C}$ hold). pUC19 DNA [New England Biolabs (UK) Ltd., Hitchin, Hertfordshire, England, UK] was used as PCR template. PCRs $(100 \mu \mathrm{L})$ were carried out in $1 \times$ PCR buffer [10 mM Tris- $\mathrm{HCl}(\mathrm{pH} 8.3), 50 \mathrm{mM} \mathrm{KCl}, 1.5$ $\mathrm{mM} \mathrm{MgCl} 2$ ] with $2.5 \mathrm{U}$ AmpliTaq ${ }^{\circledR}$ DNA Polymerase (AmpliTaq Kit with buffer and $\mathrm{MgCl}_{2}$; PE Biosystems), $200 \mu \mathrm{M}$ each dNTP (Amersham Pharmacia Biotech UK Ltd.) and 0.5 pmol each primer ( $5^{\prime}$ TGC TTC CGG CTC GTA TGT $3^{\prime}$ and 5' Biotin CCA TTC GCC ATT CAG GCT 3').

For analysis by AGE, $20 \mu \mathrm{L}$ of PCR product were loaded directly onto a 3\% NuSieve ${ }^{\circledR}$ 3:1 agarose gel (Flowgen Instruments Ltd., Lichfield, Staffordshire, England, UK) containing $0.005 \%$ ethidium bromide. The products were visualized using 
a Gel Print Workstation and Photofinish ${ }^{\circledR}$ software (MWGBiotech UK Ltd., Milton Keynes, Bucks, England, UK). DNA yields were determined using the GeneQuant II RNA/DNA Calculator (Amersham Pharmacia Biotech UK Ltd.).

Oligonucleotides were designed using the $\mathrm{OLIGO}^{\circledR} 5.0$ Primer Analysis Software (MedProbe AS, Oslo, Norway). Capture probes were designed to be internal within the target DNA to avoid competition with the PCR primers.

For analysis by DARAS, $10 \mu \mathrm{L}$ of biotin-labeled PCR product were diluted to $100 \mu \mathrm{L}$ in sample buffer [ $10 \mathrm{mM}$ Tris$\mathrm{HCl}(\mathrm{pH} 8.3), 50 \mathrm{mM}$ sodium citrate, $80 \mathrm{mM}$ sodium chloride, $8 \mathrm{mM}$ magnesium chloride, $0.1 \%$ Triton $\left.{ }^{\circledR} \mathrm{X}-100\right]$. The sample was denatured on-line at $95^{\circ} \mathrm{C}$ for $5 \mathrm{~min}$ and hybridized for $10 \mathrm{~min}$ at $37^{\circ} \mathrm{C}$ (unless otherwise stated). Streptavidin-alkaline phosphatase (SAP) conjugate incubation was carried out at $37^{\circ} \mathrm{C}$ for $10 \mathrm{~min}$. The first step of the detection reaction was carried out in two incubations, each of $50 \mu \mathrm{L}$ of substrate at $30^{\circ} \mathrm{C}$ for $5 \mathrm{~min}$, followed by the addition of 100 $\mu \mathrm{L}$ of amplifier to initiate color generation.

\section{System Design}

The key to the DARAS system is target-specific microbeads, incorporating covalently attached oligonucleotide probes (Figure 1, Inset), which remove the complementary sequence from an applied sample. The micro-beads are contained within a purpose-designed reaction column (Figure 1, Inset), which, together with the DARAS instrument and software, automate the analysis of PCR samples using the precise fluid handling, temperature control and signal detection capabilities of the system.

The process of DNA capture involves the temperature-dependent hybridization of DNA onto the target-specific microbeads (Figure 2A). Once hybridized, nonspecific material is removed by flow-through washing, and the captured DNA is detected by a DNA-biotin-SAP complex linked to a two-stage color generation system (1) (Figure 2B).

Samples and reagents are presented to the instrument (Figure 1) in two reagent trays, each consisting of up to 8 individual strips of 12 wells held in a microplate frame. The reagent trays are located on a removable platten that acts as a portable workstation. Sample and reagent handling is achieved by simple pipetting operations from the reagent tray combined with mixing within the reaction column.

Fluid handling for each of the twelve lines is achieved using individual syringe pumps that operate within a range of $10-100 \mu \mathrm{L}$, with performance equivalent to digital pipets. The DARAS instrument maintains a continuous fluid line

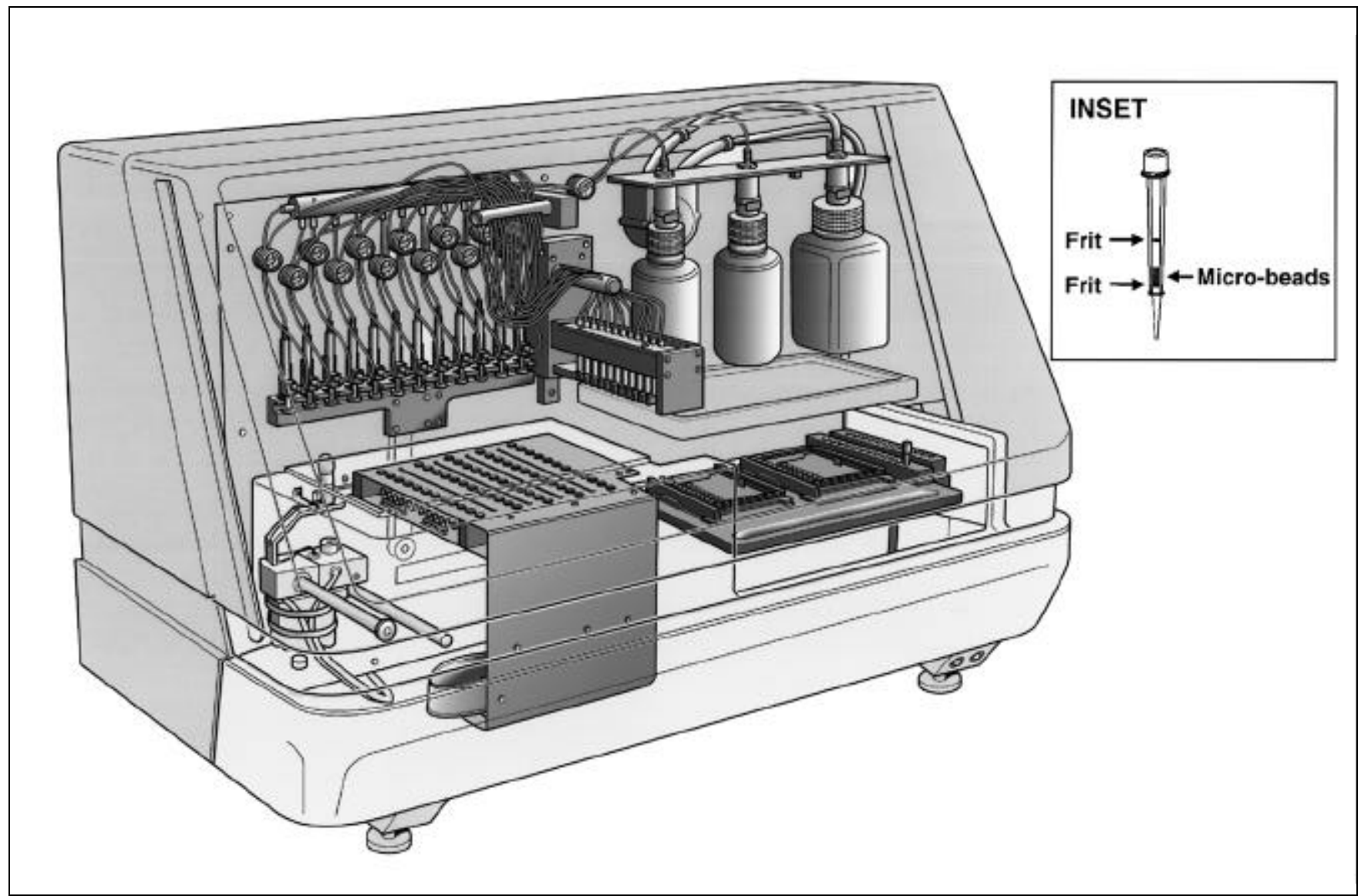

Figure 1. The DARAS instrument is a fully automated workstation comprising four modules capable of single axis movement. Heater blocks (pink) and reagent/sample platten (green) move along the X-axis to locate beneath the column head. The column head (in blue along with the fluid handling system) moves along the Z-axis to allow fixed temperature incubation and aspiration/dispensing of samples and reagents. A spectrophotometer (yellow), for either kinetic or end-point determinations at $492 \mathrm{~nm}$, moves along the Y-axis. (Inset) The disposable DARAS reaction column contains micro-beads held in a reaction zone by two frits. Amino-modified oligonucleotides are covalently linked to pre-activated micro-beads using a simple 30-min linkage protocol [reaction columns and linkage reagents are supplied in the DARAS OPTIONS Kit (Tepnel Life Sciences PLC]. Unlinked reaction columns can be stored for up to 24 months at $2^{\circ}-8^{\circ} \mathrm{C}$; linked columns can be stored for up to 12 months in storage buffer at $2^{\circ}-8^{\circ} \mathrm{C}$. Each reaction column contains micro-beads with a total surface area approximately $2000 \times$ greater than the well of a standard microplate and a binding capacity in excess of $10^{14}$ binding sites. 
from two buffer reservoirs (100 mL each) by means of a column head assembly to each of the 12 reaction columns. During washing, fluid is directed to a wash station attached to the platten.

Temperature control is performed within a series of four heater blocks into which the reaction columns descend. These can be set individually to temperatures ranging from $30^{\circ}-$ $98^{\circ} \mathrm{C}$. Accurate temperature control $\left( \pm 0.1^{\circ} \mathrm{C}\right)$ and quick thermal response within the reaction column (greater than $1^{\circ} \mathrm{C} / \mathrm{s}$ ) enable the rapid generation of reproducible results.

The DARAS instrument is controlled by a Windows ${ }^{\circledR}(\mathrm{Mi}-$ crosoft, Redmond, WA, USA) graphical user interface, which can execute prewritten protocols and allows the user to write or modify protocols from a set of simple command icons. The software also includes a setup notebook to log experimental details and automatic transfer of results files to spreadsheet software, such as Microsoft ${ }^{\circledR}$ Excel $^{\circledR}$ (Microsoft), for analysis.

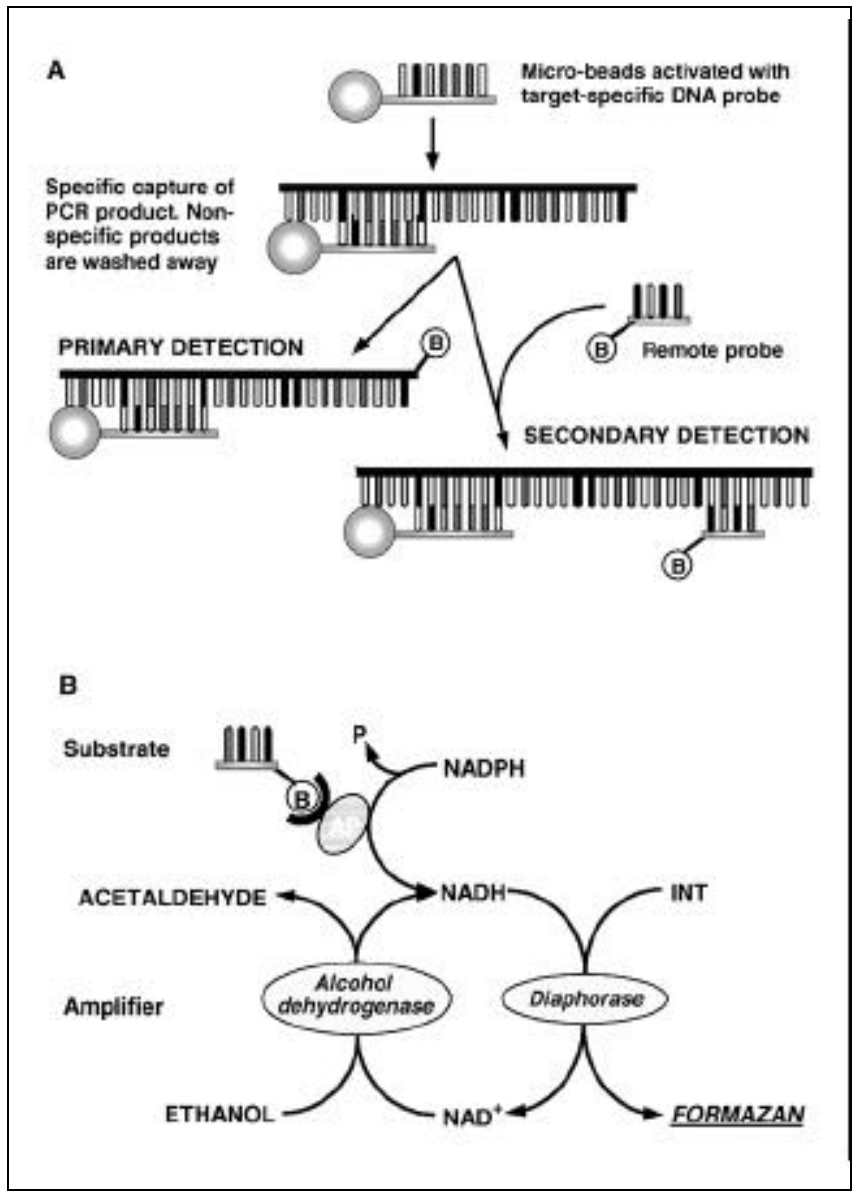

Figure 2. Diagram of the DARAS capture and detection chemistry. (A) PCR product is captured onto target-specific micro-beads by temperature-dependent hybridization. The product is biotin-labeled, either directly, using a biotin-labeled PCR primer, or indirectly, using a biotin-labeled secondary probe complementary to the captured strand. All interfering substances, such as free biotin-labeled oligonucleotides, are removed by washing. (B) Captured DNA (biotin-labeled) is incubated with SAP to form a DNA-biotinSAP complex. Washing removes the excess SAP, and the complex is incubated with NADPH, which is converted by the alkaline phosphatase to NADH. NADH is an essential component in an enzyme amplification reaction in which two enzymes, alcohol dehydrogenase and diaphorase, catalyze the cyclic interconversion of NADH and $\mathrm{NAD}^{+}$, and for each turn of this redox cycle, one molecule of formazan (red color) is produced, which can be measured spectrophotometrically at $492 \mathrm{~nm}$.

\section{RESULTS AND DISCUSSION}

The results described here were achieved using a standard capture model (a 294-bp PCR product derived from pUC19) with an internal capture site, complementary to oligonucleotide DOL006 (Figure 3), adjacent to one of the primer sites.

\section{Functional Binding Capacity}

The binding capacity of the micro-beads was determined using a competitive assay that involved challenging the capture oligonucleotide (DOL006) with mixtures containing biotinylated and non-biotinylated complementary oligonucleotide (DOL033). The response can be modeled mathematically, and, from the quantities of oligonucleotides used, an estimate can be made of the functional binding capacity. From such competition experiments, the binding capacities of the columns have been shown to be fully controllable and can exceed 100 pmol per reaction column (data not shown).

\section{Reproducibility}

Oligonucleotide capture probes were linked to microbeads using an on-line linkage reaction. To assess the reproducibility of the linkage reaction, 32 sets of 12 linkages were performed and tested using the standard capture model. The results demonstrate a coefficient of variation for the linkage reaction of 3\%-12\% (intra-assay variation) and $12 \%$ (interassay variation) (data not shown).

\section{Capture Response and Specificity}

Using the standard capture model, six alternative capture probes were designed that contained 1-6 mismatches compared to DOL006 (Figure 3). Figure 3 shows the relative capture response of the PCR product in each of these systems.

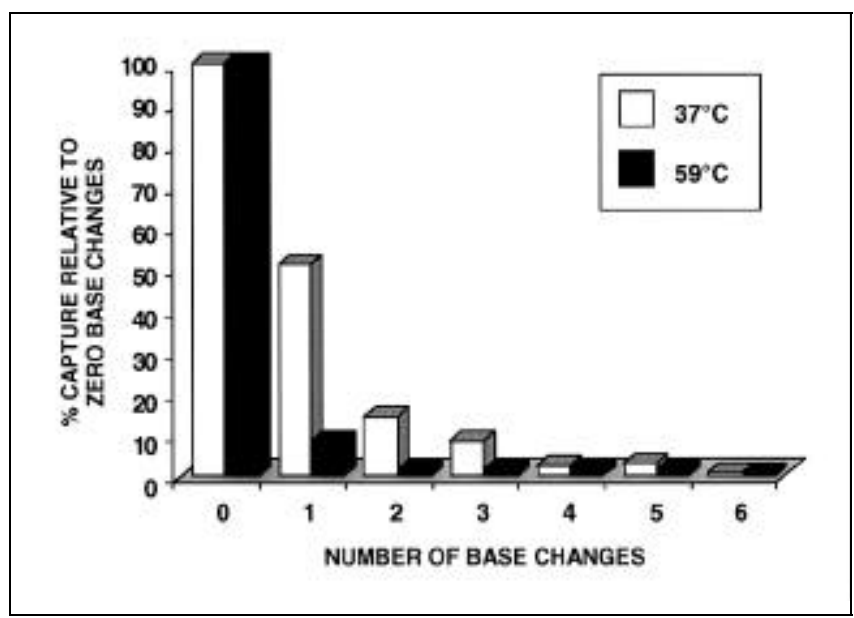

Figure 3. Detection of a biotin-labeled, 294-bp product using mismatched supports. The capture response at $37^{\circ}$ and $59^{\circ} \mathrm{C}$ of the mismatched sequences is expressed relative to the respective capture response of the complementary sequence. The oligonucleotides are listed in order of increasing number of mismatches (in bold): DOL006 5'-AGC GGA TAA CAA TTT CAC ACA GGA-3'; one mismatch 5'-AGC GGA TAA CAA CTT CAC ACA GGA-3'; two mismatches 5'-AGC GGA TAG CAA CTT CAC ACA GGA3'; three mismatches 5'-AGC GGA TAG CAA CTT CAC ACA GGT-3'; four mismatches 5'-AGC GGA TAG CAA CTT CAC ACT GGT-3'; five mismatches 5'-AGC GGA TAG CAA CTT CAG ACT GGT-3'; six mismatches 5'-AGC GGA TAG CAA CTT CTG ACT GGT-3'. 


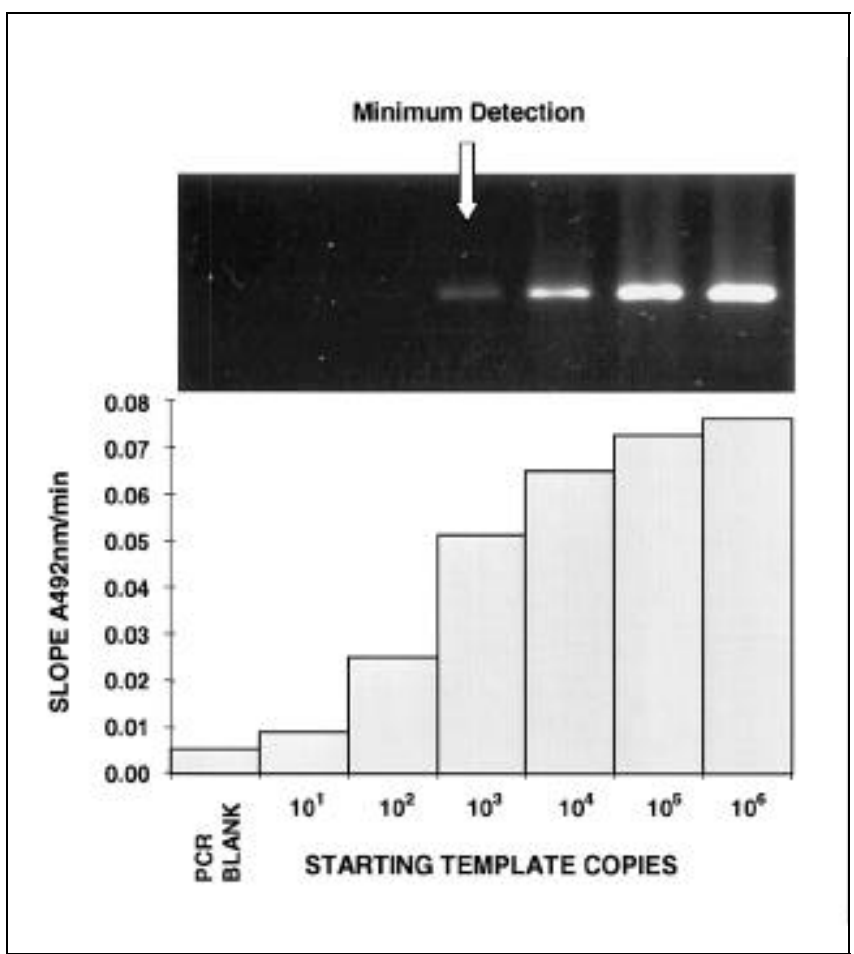

Figure 4. Comparison of detection sensitivity using DARAS and AGE. Increasing amounts of starting template (pUC19 DNA) were amplified using 30-cycle PCR and an aliquot subjected to analysis using AGE and DARAS. A PCR blank containing no template DNA was included as negative control.$$
\text { . }
$$

The results demonstrate that at $37^{\circ} \mathrm{C}$ the presence of a single base change leads to a significant reduction in the capture response, and that additional mismatches further reduce this response. Under optimized conditions (hybridization at $59^{\circ} \mathrm{C}$ ), DARAS exhibits single base discrimination.

\section{Sensitivity-DARAS vs. AGE}

The sensitivity of DARAS was compared to that of AGE by defining the minimum detection level (MDL) for each technique. Standard PCRs were performed using between $10^{1}$ and $10^{6}$ input copies of pUC19 template. The products of these reactions were analyzed using DARAS and AGE. Figure 4 shows the estimated MDL, post PCR, for DARAS to be $10^{1}$ input template copies, while the estimated MDL, post $\mathrm{PCR}$, for AGE detection is at least $10^{3}$ input template copies.

Further analysis of detection sensitivity has been performed using PCR products derived from a range of sample types (e.g., cell culture, blood, feces, meat and fiber) confirming the improvement in detection sensitivity (data not shown).

\section{CONCLUSIONS}

The principal application for DARAS is the detection and sequence confirmation of PCR products. DARAS can specifically capture target DNA present in a complex reaction mix- 
ture and remove contaminants by washing to produce a "clean" DNA target. This can then be hybridized with labeled oligonucleotide probes to confirm its sequence identity. Alternatively, the "clean" DNA target can be copied using DNA polymerase enzymes, which extend the DNA strand from the capture probe, to create an immobilized complementary copy of the target molecule. This allows the possibility of building up a "DNA library" of experiments for reference.

DARAS can further enhance the utility of PCR in two ways: $(i)$ by providing positive identification of target DNA at low levels, for example, detection of at least $1 \mathrm{ng}$ of PCR product specific to verotoxigenic Escherichia coli (VTE) (6); and (ii) by reducing the number of cycles required for detection, such that in experiments to detect VTE and Listeria monocytogenes, the MDL was achieved after 15 cycles using DARAS compared to 19 cycles using AGE (unpublished data). Moreover, the ability to discriminate single base mismatches enables DARAS to be used for mutation detection. For instance, tests have shown that DARAS is able to distinguish between patient samples containing wild-type or mutant copies of the BRCAl gene (3).

The sensitivity and specificity of the micro-bead capture system used by DARAS creates a new opportunity for analysis of nucleic acids. Potential applications include the detection of PCR products, point mutation analysis, multiple allele specific oligonucleotide (ASO) probing and sequence-specific purification. The combination of flexibility and automation makes DARAS a unique tool for life science research.

\section{ACKNOWLEDGMENTS}

We thank Catherine Sanders for production of the graphics and Simon Dixon, Tina Walker and Peter Highfield for their comments on the manuscript.

\section{REFERENCES}

1.Bates, D.L. 1987. Enzyme amplification in diagnostics. Trends Biotechnol. 5:204-209.

2.Beaucage, S.L. and M.H. Caruthers. 1981. Deoxynucleoside phosphoramidites - a new class of key intermediates for deoxypolynucleotide synthesis. Tetrahedron Lett. 22:1859-1862.

3.Black, D. 1998. Detecting risky mutations. Med. Lab. World July/August, p. 7-8.

4.Haff, L., J.G. Atwood, J. DiCesare, E. Katz, E. Picozza, J.F. Williams and T. Woudenberg. 1990. A high-performance system for automation of the polymerase chain reaction. BioTechniques 10:102-112.

5.Mullis, K.B. and F.A. Faloona. 1987. Specific synthesis of DNA in vitro via a polymerase catalyzed chain reaction, p. 335-350. In $\mathrm{R}$. Wu (Ed.), Methods Enzymology, Vol. 155. Academic Press, San Diego.

6.Short, J. and N. Wisely. 1998. Automated gel-free analysis of food pathogens. Nature UK Product Review May, p. 10.

Address correspondence to Dr. Allan Brown, Tepnel Life Sciences PLC, Scotscroft Building, Wilmslow Road, Didsbury, Manchester, M20 2RY, England, UK. Internet: abrown@ tepnel.co.uk 